\title{
ASSESSMENT OF BIOLOGICAL PARAMETERS THAT (INFLUENCE) AFFECT THE QUALITY OF LIFE IN A GROUP OF PATIENTS WITH METABOLIC SYNDROME
}

\author{
OVIDIU BOITOR ${ }^{1}$, LAURA ȘTEF ${ }^{2}$, GABRIELA BOȚA $^{3}$, ROMEO MIHĂILĂ $\breve{A}^{4}$ \\ ${ }^{1}$ PhD candidate "Lucian Blaga" University of Sibiu, ${ }^{2,3,4}$ "Lucian Blaga” University of Sibiu, Clinical County Emergency Hospital, Sibiu
}

Keywords: health-related quality of life, metabolic syndrome, diabetes type 2

\begin{abstract}
The study included a group of 42 patients with metabolic syndrome and 32 patients without metabolic syndrome. The following biological data: BMI, blood pressure, type 2 diabetes, low HDL cholesterol levels were statistically compared using the ANOVA test. To assess the impact on quality of life, patients in both groups completed the EQ-5D-3L questionnaire. To verify the statistical confirmation of the results we used the Chi 2 test. In order to correlate the results with the gender and age of the patients, we formed the following age groups 45-54 years, 55-64 years, 65-74 years and over 75 years. We found that the dimensions that affect the quality of life differ depending on the age group as follows: in the 55-64 age group pain / discomfort predominates $p=0.009$ and in the 65-74 age group the mobility and self-care dimensions $p=0.043$ predominate. We did not obtain statistical confirmation by the Chi 2 test in patients with metabolic syndrome and the variable blood pressure Chi $2=5.27$ and $p=0.072$
\end{abstract}

\section{INTRODUCTION}

The concept of health-related quality of life (HRQoL) has seen an increase in the approach in recent decades following the improvement of socio-economic conditions and health care services, which have provided increasing life expectancy. In essence, research on quality of life is based on the patient's point of view on their own health and more specifically whether through the care received and the treatments applied in case of illness his health improves or not.

Numerous tools are described in the literature that are designed to assess changes in the quality of life addressed to groups of patients affected by some conditions but also measurements that assess the individual impact. Individual measurements can cover a wide range of aspects that can adversely affect physical functioning, emotional well-being, or the ability to engage in social activities or work in the profession.

The use of HRQoL indicators has applications in the evaluation of treatment protocols in clinical trials or health surveys. Another use of the data obtained through the indicators for measuring the quality of life is in the economic evaluation of the medical treatments applied in different health care systems (state or private).(1)

The EuroQol 5D-5L questionnaire (EQ-5D) was initiated over 30 years ago and then adapted and perfected so as to correspond to the interviewees. It addresses 5 dimensions of health: mobility, self-care, regular activities, pain / discomfort and anxiety / depression. These correspond to 3 levels of damage: slightly affected, significant damage and severely affected.

Through them, it is desired to be able to identify changes in health affected by diseases or treatments applied. Practically the questionnaire contains two pages. On the first is the descriptive system EQ-5D and on the second page the visual analog scale with values from 0 to 100 similar to the scale of a thermometer - EQ-VAS.

Explaining and completing the questionnaire takes about 2-3 minutes. The number of levels in all 5 dimensions can be 3 or 5 . Due to the five dimensions and three levels, the response variants can be 125 , and for the five-level variant there can be 3125 potential health conditions. $(1,2)$

The possible levels for the first four dimensions are: none (no problem), some problems and a lot of problems. The levels of the worried / sad / unhappy feeling dimension are "no", "little" and "very".

The graphic representation EQ-VAS - (European Quality of Life Visual Actual Status) reflects the current status of the health condition, includes on the second page a vertical scale of $20 \mathrm{~cm}$ which is calibrated and assigns values from 0 for the worst health condition until at the value of 100, at the top of the scale, for the best state of health. Interviewees are asked to mark with $X$ an integer value that they appreciate for their health at the time of examination. This value will then be entered in the box next to it. By this marking it is possible that after a certain time, the patient marks the evolution of the health condition before and / or after the performed treatments.

These questionnaires are adapted both in the literal and digital version or on the phone, tablet or through proxies. The questionnaires were translated and adopted with the help of experts, in over 200 languages, so that they correspond faithfully, in the expression of the terms, with the cultural level of the examined community. $(3,4,5)$

Following the completion of the descriptive questionnaire, a 5-digit EQ-5D health profile results. In this way a value can be attached to each EQ-5D health condition to reflect as accurately as possible the preference of a community or population and to allow statistical comparison.

Another quality of the numerical value attributed to a

${ }^{1}$ Corresponding author: Laura Ștef, Str. Lucian Blaga, Nr. 2A, Sibiu, România, E-mail: laura.stef@ulbsibiu.ro, Phone: +40269 436777 Article received on 10.08.2021 and accepted for publication on 02.09.2021 


\section{PUBLIC HEALTH AND MANAGEMENT}

certain state of health is the possibility to economically evaluate medical interventions to restore health. In this way, for example, the costs of health services for the same condition in different countries or the cost-effectiveness of services needed to treat different conditions with an impact on quality of life can be compared.(5-16)

Through these studies we have the right to know to what extent the biological parameters involved in defining metabolic syndrome (BMI, central obesity, type 2 diabetes, hypertension) influence the quality of life in a group of patients who were hospitalized in the cardiology and diabetes departments of SCJU Sibiu, during 2019. The psycho-social indicator chosen for this purpose was EQ-5D-3L with the translation adapted for the Romanian language.

\section{AIM}

The exponential increase in the number of people with obesity, diabetes, high blood pressure or dyslipidemia in the working age population causes significant changes in collective health. We aim to establish the connections that can be made between these diseases and the decrease in quality of life.

\section{MATERIALS AND METHODS}

In this study we randomly compiled an experimental group of 42 patients, hospitalized with ages between $52-82$ years (17 males and 25 females) who could be included in the metabolic syndrome, according to the criteria of NCEP-ATD III and FDI. $(4,5)$

The control group of patients who did not present with metabolic syndrome was composed of 32 patients aged between 45-54 years (16 males and 16 females) clinically healthy, who did not present current health problems and who presented for dental control and treatments in the Dentistry Outpatient Clinic of SCJU Sibiu.

Only patients who gave their consent and signed the informed consent were included in the two groups. Patients undergoing treatment for liver, tumor, blood or gestation were excluded from the study.

The biological data were obtained by anamnesis and consultation of the clinical record of hospitalization and of outpatients by medical letter requested from the family doctor. Other data regarding the weight and waist circumference were obtained by weighing and measuring with the homologated devices from the SCJU Sibiu endowment, according to the recommendations from the literature.

The data obtained were recorded in individual examination sheets which also recorded the following: age, gender, living environment, income per family member, school preparation, food preferences, regular consumption and the amount of alcohol, if it is or has been smoker and how many cigarettes / day, if he practices sports at least 3 times / week for at least 30 minutes. Also on this occasion we asked the patients to fill in the printed questionnaire form EQ-5D-3L, adapted to the Romanian language. $(3,4)$

In order to obtain the values of the biological markers, biological analyses were performed from the venous blood, collected after at least 12 hours of fasting, in the morning between 7-10. Blood pressure was measured with approved sphygmomanometers from the clinical department, measuring blood pressure for 10 minutes on both hands and recording the average of the 3 sets of measurements.

We calculated BMI by dividing the weight expressed in kilograms by the square of the height expressed in meters $(\mathrm{kg}$ / m2) and we classified the patients in the following categories: pre obese for values $26-29.9 \mathrm{~kg} / \mathrm{m} 2$, obese grade I for values between $30-34,9 \mathrm{~kg} / \mathrm{m} 2$, obese grade II for values between $35.0-39.9 \mathrm{~kg} / \mathrm{m} 2$ and grade III for values $>=40 \mathrm{~kg} / \mathrm{m} 2$.
In order to obtain results as close as possible to the social conditions and health condition, we divided the groups studied according to age criteria of 10 years, into 5 categories as follows: category 45-54 years, category 55-64 years, category 65-74 years and category over 75 years.

All statistical analyses were performed in SPSS version 17.0 of Windows, where a $p$ value of 0.05 was considered statistically significant. $(16,17)$ Chi-square (2) tests were performed to assess whether metabolic syndrome and BMI scores, patient gender, HDL cholesterol, EQ-5D-3L index and EQ-VAS value, blood pressure, diabetes vary significantly.

A chi-square statistic is a way to show a relationship between two categorical variables. The chi-square statistic is a unique number that quantifies the difference between the observed number and the expected number if there was no relationship in the population.

A small value for chi-square (less than the critical value in the chi-square table) means that there is a high correlation between the two data sets. (Chi square obtained <Chi square table means statistical significance). A p-value can also be used. Low p-values (below 5\%) usually indicate that there is a high correlation between the data sets analysed and implicitly that the test results are significant.

The single analysis of variance (ANOVA) was also performed for EQ-5D and EQ-VAS measures, classified according to the following parameters: BMI, blood pressure, diabetes, HDL-cholesterol and metabolic syndrome.

The ANOVA analysis tests the null hypothesis, which states that samples from all groups are extracted from populations with the same average values. Groups or levels are different groups within the same independent variable. The ANOVA analysis produces an $\mathrm{F}$ statistic that expresses the ratio between the calculated variance between the means and the variance in the samples.

The critical value is the number that the test statistic must exceed in order to reject the test at the $\mathrm{p} \%$ significance level. If $\mathrm{F}$ is greater than the critical value, the null hypothesis is rejected, concluding that there is strong evidence that the means of the independent (unrelated) groups are unequal

\section{RESULTS}

The socio-demographic characteristics collected in our research included age, sex, level of education, area of residence and monthly income per family member. These are shown in table no. 1.

Table no. 1. Socio-demographic characteristics of Health Survey sample

\begin{tabular}{|c|c|c|c|}
\hline \multirow{2}{*}{ Sample } & Total & Females & Males \\
\hline & $\mathrm{N}=74$ & $\mathrm{n}=43$ & $\mathrm{n}=31$ \\
\hline Age, mean & 66,1 & 65,7 & 66,5 \\
\hline \multicolumn{4}{|c|}{ Age category, years, $\%$} \\
\hline $45-54$ & 2,7 & - & 6,5 \\
\hline $55-64$ & 39,2 & 48,8 & 25,8 \\
\hline $65-74$ & 45,9 & 39,5 & 54,8 \\
\hline $75+$ & 12,2 & 11,6 & 12,9 \\
\hline Gender, $\%$ female & & 58,1 & \\
\hline \multicolumn{4}{|l|}{ Education level, \% } \\
\hline high-school & 74,3 & 79,1 & 67,7 \\
\hline university & 25,7 & 20,9 & 32,3 \\
\hline \multicolumn{4}{|c|}{ Area of residence, $\%$} \\
\hline Metropolitan & 41,9 & 39,5 & 45,2 \\
\hline Regional & 58,1 & 60,5 & 54,8 \\
\hline \multicolumn{4}{|c|}{ Monthly income per family member } \\
\hline$\geq 1500$ & 33,8 & 30,2 & 38,7 \\
\hline$<1500$ & 66,2 & 69,8 & 61,3 \\
\hline
\end{tabular}




\section{PUBLIC HEALTH AND MANAGEMENT}

Following the ANOVA analysis, we obtained data that reflect the variation of the metabolic syndrome depending on the parameters followed in the research: BMI, blood pressure, HDL cholesterol, EQ-VAS and diabetes. The results are presented in table no. 2 .

Table no. 2. Variation of some biological parameters that determine the metabolic syndrome

\begin{tabular}{|c|c|c|c|c|}
\hline & & & $\begin{array}{l}\text { Metal } \\
\text { synedr }\end{array}$ & $\begin{array}{l}\text { olie } \\
\text { amse }\end{array}$ \\
\hline & & & No & Yes: \\
\hline & Normal & Coent & $t$ & 0 \\
\hline & BMI & 46 With $\Rightarrow$ Mrtabelis nyatrome & 25,006 & $0 \%$ \\
\hline & Pre-obeve & Cosst & 15 & 2 \\
\hline Ban & & 46 Within Metabolis nndrome & 46,996 & 4,596 \\
\hline$\gamma^{1}=3059$ & Obese I & Coust & 7 & 16 \\
\hline & & 8. Within Metabolis sydidrome & 21.926 & $3 \pi .1 \%$ \\
\hline$p<0,001$ & Obese II & Count & 2 & 19 \\
\hline & & $\because$ Within Metsbolic anndrome & 6,346 & $45,2 \%$ \\
\hline & Obese III & Couant & 0 & 5 \\
\hline & & N) Within Metabelic syndrome & .026 & $11,9 \%$ \\
\hline & highth & Count & 0 & 3 \\
\hline Arterial tension & & If Withen Metabolis ayndrome & .056 & $11.5 \%$ \\
\hline & Jow & Cowat & 1 & 0 \\
\hline$x=-3,21$ & & N6 Withis Metabolis wyadrome & 3,136 & $\infty$ \\
\hline$p=0.672$ & normal & Covant & 31 & 37 \\
\hline & & of Within Metabolis syndrome & 96,904 & $83,1 \%$ \\
\hline Diabetes & No & Count & 22 & 16 \\
\hline & & 46. Within Metabolis syndrome & 68.86 & $38.1 \%$ \\
\hline$x^{2}=6,83$ & Yes & Count & 10 & 26 \\
\hline$p=0,009$ & & 96 Within Metabolsc igndrome & 31,316 & $61,9 \%$ \\
\hline & low & Covent & 0 & 26 \\
\hline HDL cholesterol & & as Within Metabolis anndrume & $0 \%$ & $619 \%$ \\
\hline$\gamma^{2}=70,165$ & sormal & Count & 31 & 6 \\
\hline & & 36. Within Metabolis ayndrome & 96,916 & S\% \\
\hline$p<0,001$ & risk: & Count & 1 & 16 \\
\hline & & 36 Withas Metaboles syndrome & 3,196 & $38.1 \%$ \\
\hline & good & Count & 32 & 22 \\
\hline EQ-VAS categery & & 96 Within Metabolic ayndrome & $100,0 \%$ & $52,4 \%$ \\
\hline$y^{2}=20.88$ & low & Coush & 0 & 3 \\
\hline & & S6 Within Metabelic syndrome & .036 & $11,9 \%$ \\
\hline$p<0,001$ & medium & Coist & 0 & 15 \\
\hline & & 36 Withis Metabolis nyndrome & .026 & $35,7 \%$ \\
\hline
\end{tabular}

Mean difference scores (mean difference) were calculated by performing a single analysis of variance (ANOVA), where the mean EQ-VAS scores for the "normal / no metabolic syndrome" category of patients in each group were compared with the mean EQ-VAS scores. VAS for patients with metabolic syndrome. The results are presented in table no. 3 .

Table no. 3. Mean values and standard deviation for the EQVAS score parameter

\begin{tabular}{|c|c|c|c|c|c|c|}
\hline EQVAS : & are & $\mathrm{N}$ & Morn & sta. & Metas & Sild \\
\hline & Nermal BMI & 8 & 91.88 & 2.555 & & .915 \\
\hline BMI & Precteven & 17 & 92,47 & 7,915 & 0,596 & 1,020 \\
\hline $\mathrm{F}=7 \mathrm{7y}$ & Obean 1 & 23 & 84,74 & $11,+49$ & $-7,136$ & 2,359 \\
\hline$p<0.001$ & Obene II & 21 & 83,53 & 7,305 & $-8,542$ & 1,594 \\
\hline & Obese III & 5 & 69,00 & 14,313 & $.22,875$ & 6,003 \\
\hline Dabietes & No & 38 & ER,29 & 8.764 & 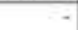 & 1,422 \\
\hline $\begin{array}{l}F=4,29 \\
p=0.042\end{array}$ & Yes & 36 & 83.22 & 12,100 & $-5,067$ & 2,017 \\
\hline Arterial tention & nocmall & 69 & 8759 & 8.561 & 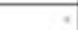 & 1,038 \\
\hline & low & 1 & 90,00 & & $2,4 !$ & \\
\hline$p<0.001$ & hiph & 5 & 61,00 & 7,416 & $-26,59$ & 3,317 \\
\hline HDL cholesterol & nocemet & 31 & 93,74 & 3,011 & - & 541 \\
\hline$F=24.55$ & lisw & 26 & T2.85 & 12.515 & $-14,696$ & 2,454 \\
\hline$p<0001$ & risk & 17 & 82,06 & 7,054 & $-11,683$ & 1,218 \\
\hline Metabedic syudronet & $N_{0}$ & 32 & 93,63 & 3,035 & $\rightarrow$ & .536 \\
\hline $\begin{array}{l}F=49,31 \\
p<0.001\end{array}$ & Yea & 42 & 79,38 & 10,734 & $-13,744$ & 1,658 \\
\hline
\end{tabular}

The mean scores and standard deviation for the EQ5D-3L measure (five-digit number assigned to each patient) were classified according to the following characteristics: BMI, blood pressure, diabetes, HDL cholesterol, and metabolic syndrome. They are shown in table no. 4

Table no. 4. Mean values and standard deviation for the EQ5D-3L index

\begin{tabular}{|c|c|c|c|c|c|c|}
\hline \multicolumn{2}{|c|}{ EQ-SD-3L, index } & \multirow{2}{*}{$\frac{N}{s}$} & \multirow{2}{*}{$\begin{array}{c}\text { Mana } \\
, 9268\end{array}$} & \multirow{2}{*}{$\begin{array}{c}\text { Sod. } \\
\text { Desiatice }\end{array}$} & \multirow{2}{*}{$\begin{array}{c}\begin{array}{c}\text { Mean } \\
\text { diff }\end{array} \\
\end{array}$} & \multirow{2}{*}{ 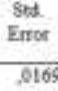 } \\
\hline & Noenal 9MI & & & & & \\
\hline BMI & Preobere & 17 & 9344 &, 9888 & 0076 & .0215 \\
\hline$F=1,49$ & Obese ? & 23 & 8373 & 2959 & 0894 & .0617 \\
\hline$g=0.216$ & Obese II & 21 & .8590 & , 1087 & -0660 & 0237 \\
\hline & Obese III & 5 & .7364 & 1963 & 1904 & 2978 \\
\hline Diabetes & No & 38 & 9286 & 8979 & 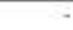 & 5243 \\
\hline$p=0,005$ & Yea & 35 & , 2058 & .2453 & -1228 & .0409 \\
\hline Arterial tentaba & netmal & 68 & .8877 & 1270 & - & 2155 \\
\hline$E$. & bow & 1 & 1,0006 & & .1123 & \\
\hline$p=0,002$ & bigh & 5 & 5862 & $\$ 326$ & -3011 & 2382 \\
\hline HDL chuleiterst & nermal & 31 & 2451 & .0741 & - & .0133 \\
\hline $5-8,3$ & low & 26 & .7557 & .2794 & -1864 & 0548 \\
\hline$p=0,001$ & riak & 17 & 3984 & .0527 & .0461 &, 0128 \\
\hline Metabolie syndrome & $N_{0}$ & 32 &, 9454 & 0730 & $\longrightarrow$ & .0129 \\
\hline $\begin{array}{l}F=10,16 \\
p=0,002\end{array}$ & Yea & 42 & anos & 2304 & -1349 & 0355 \\
\hline
\end{tabular}

The five dimensions that measure quality of life impairment in patients with metabolic syndrome varied by age group. The data obtained by the analysis of the variant are presented in table no. 5 .

Table no. 5. Variation by age groups of the 5 dimensions of quality of life in patients with metabolic syndrome

\begin{tabular}{|c|c|c|c|c|c|c|c|c|c|c|c|c|}
\hline Ascrove Gano & \multicolumn{3}{|c|}{148} & \multicolumn{3}{|c|}{$8 \% 4$} & \multicolumn{3}{|c|}{ H.4 } & \multicolumn{3}{|c|}{ "*- } \\
\hline 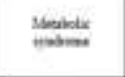 & \$o & $\begin{array}{l}\text { The } \\
\text { xतs }\end{array}$ & $\dot{J}$ & $\begin{array}{l}36 \\
+80\end{array}$ & $\begin{array}{l}\text { Ta } \\
\text { *C) }\end{array}$ & 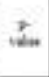 & $\begin{array}{l}\text { No } \\
\text { Nou }\end{array}$ & $\begin{array}{l}Y_{m}= \\
+\infty\end{array}$ & $D$ & $\begin{array}{l}\mathrm{Na}_{\mathrm{a}} \\
\text { - }\end{array}$ & $\begin{array}{l}\text { Tot } \\
\text { sece }\end{array}$ & $\therefore$ \\
\hline neabt; & Qका & 000 & . & 0,00 & 1009 & 900 & 0,000 & $7^{2}$ & 0,045 & (1) & ${ }^{1} 163$ & $a+9$ \\
\hline Sthere & 900 & $0 \%$ & - & $1 \Leftarrow t, 1$ & גi & a.ts & 000 & $\cos ^{3}$ & (0,03 & 19 & 3 & $0,1,4$ \\
\hline Vinel Átrinau & $90 \%$ & Q00\% & + & ${ }^{3}$ & asi & \&A & $i^{4}$ & ${ }^{3}$ & a.e & ain & $a^{2}$ & $t$ \\
\hline Ran Duradkn & 90 & ${ }_{100}^{1}$ & 4.197 & oris & 14 & 0,006 & $\cos ^{2}$ & osis & 0,111 & gini & 4 & Q.24] \\
\hline trout Dequausen & $00 \%$ & $0 \%$ & - & 10,1 & aม่ & ane & ogs & aisa & cons & 4 & $\cos _{0}^{\prime}$ & atet \\
\hline
\end{tabular}

Figure no. 1. Comparative representation of the values of EQ-Vas and EQ-5D-3L score
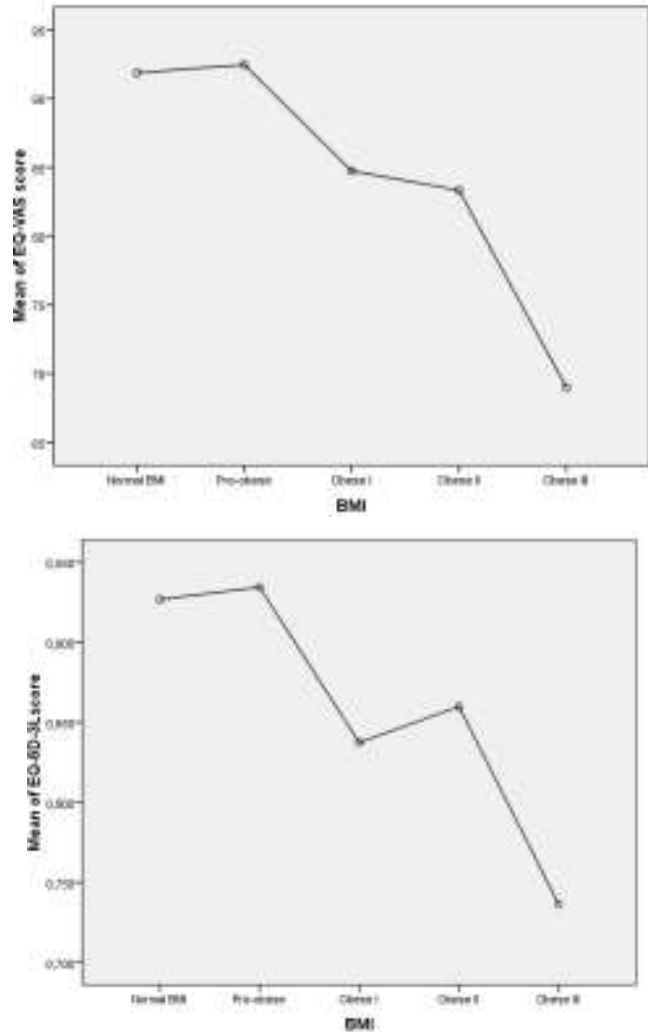


\section{PUBLIC HEALTH AND MANAGEMENT}

Unique analysis of variance (ANOVA), where the average EQ-5D-3L scores for the "normal" category of patients in each group was compared with the average EQ-5D-3L scores for patients in each of the other categories in the same group. Figure no. 1 graphically compares the mean values of the EQVAS and EQ-5D-3L scores for the five categories of the BMI index, respectively.

\section{DISCUSSIONS}

The main advantage of using the EuroQol questionnaire - 5 Dimensions (EQ-5D) is the very high degree of use in research practice for over 20 years, which has led to a permanent improvement and adaptation. This makes this questionnaire compatible with many social and economic situations in different groups, communities or geographical areas.

Another advantage of the questionnaire is that it allows the investigation of a large number of impairments of quality of life. These can be due to various diseases from diabetes, to osteo-articular diseases, cancer or mental disorders, disorders of various internal organs or metabolic disorders. The data obtained can be used both to compare the impact on the quality of life of some communities/populations in different areas, and to the pharmaco-economic analyzes of some therapeutic procedures, expressed by quality-adjusted life years. $(14,15)$

It can be seen from the analysis of table no. 1 which shows the socio-demographic structure that, in the groups in our study, female patients predominate $(58 \%)$, in the age group 55-64 years, with an average level of education (79\%), who come from rural areas $(61 \%)$ and with an income per family member $<1500$ lei $(70 \%)$.

Analyzing the BMI index varied according to sex (p $=0.014)$, HDL cholesterol level $(\mathrm{p}<0.001)$ and EQ-VAS score $(p=0.006)$, respectively. In the pre-obesity category, male subjects predominate $(70.6 \%)$, but only female subjects have an appropriate body mass index $(100 \%)$. Regarding the degree of obesity III, it is strongly associated with the level of HDL cholesterol below the normal value $(80 \%)$ while an HDL value considered normal is correlated with an optimal BMI index $(87.5 \%)$ only in the category included in the pre- obesity $(88.2 \%)$.

The majority of subjects without metabolic syndrome $(46.9 \%)$ are in the pre-obesity group and the largest proportion $(45.2 \%)$ of the subjects in the sample with metabolic syndrome are in obesity group II. From the analysis of the results presented in table no. 4 we observe a strong correlation between metabolic syndrome and type 2 diabetes $(p=0.009)$, HDL cholesterol ( $p<0.001)$ and EQ-VAS score $(\mathrm{p}<0.001)$.

The magnitude of the variation is demonstrated by the fact that $68.8 \%$ of subjects without metabolic syndrome do not have diabetes, while $61.9 \%$ of subjects with metabolic syndrome also have diabetes. A very large proportion of the sample that does not show metabolic syndrome (96.9\%) have normal HDL cholesterol.

The strong correlation between the metabolic syndrome and the EQ-VAS score is demonstrated by the good value of the score (higher than 80 and therefore the "good" category) for the whole sample $(100 \%)$ without metabolic syndrome, compared to a good score EQ-VAS for only $52.4 \%$ of subjects with metabolic syndrome.

It can be seen from the results presented in table no. 5 that the highest averages of the EQ-VAS score are reached within the BMI group for subjects in the normal and preobesity categories. Within the same group, the grade III obesity category has the lowest average of EQ-VAS scores. A significantly lower average EQ-VAS score is found in subjects with high blood pressure (BP> 135/90 $\mathrm{mmHg}$ ). Also, for subjects in the category of those with HDL cholesterol below the normal limit (but without a degree of risk) and respectively for subjects in the category of those with metabolic syndrome, there is a deterioration of the average EQ-VAS scores.

The analysis of the data presented in table no. 6 shows that in the case of measure EQ-5D-3L (dependent variable), the ANOVA test does not provide adequate results to reject the null hypothesis formulated for the BMI group. Thus, $\mathrm{F}=1.49$ is lower than the critical value and the significance level $p=0.215>0.05$. Therefore, it cannot be stated that the averages of the EQ-5D-3L scores differ statistically significantly between the categories in the BMI group.

For the other groups (diabetes, blood pressure, HDL cholesterol, metabolic syndrome) there is a correlation of the results obtained in relation to the EQ-VAS measure.

Following the ANOVA analysis, in this study we obtained a lack of statistical significance between the calculated values of the body mass index (BMI) and the EQ5D-3L score $(p=0.216)$. I consider that this value can be explained in part by limiting the answer options of the questionnaire to only 3 possible degrees of impairment: low impairment, moderate impairment and severe impairment of the 5 categories of diseases that determine the assessment of quality of life as a whole.

On the other hand, this lack of significance can also come from the misunderstanding due to health knowledge, level of education, geographical environment income per family member or other socio-economic conditions, by the respondents, of the significance of the imposed limits. I estimate that this deficiency could be removed by using the EQ-5D-5L variant, which through the 5 variants of quantifying the degree of functional impairment and through an explicit collaboration with respondents.

The most common association of the conditions that make up the metabolic syndrome is type 2 diabetes (T2DZ). And in our study we found that about $41 \%$ of patients in the group with metabolic syndrome also have diabetes for at least 2 years. Of these, about $92 \%$ have poor control of glycemic parameters, represented by increased values of $\mathrm{HbA} 1 \mathrm{c}>8 \%$, a correlation found in other studies conducted in Europe.(18)

The EQ-5D-3L index for patients with diabetes obtained in our research equal to $0.80(p<0.05)$ is comparable to the data reported in other recent research. Thus, various studies report values ranging from 0.61 in Greece, 0.64 in the United Kingdom, Italy, Canada, Finland to 0.80 in the US and 0.84 in Spain.(19-22) The differences between them can be explained by different inclusion criteria, different socioeconomic elements, different cultural degrees and even different health conditions offered by health systems in industrialized countries.

Regarding the subjective assessment of health status through the EQ-VAS index, the values obtained in the current research had an average value of 84 . This value is comparable to the values reported in numerous recent studies in which the following values are reported: 56 in the UK , 59 in Italy, 60 in Greece, 78 in Australia and New Zealand. $(21,22)$

Regarding the EQ-5D index, the most frequent health conditions reported by the patients in the experimental group were in the state of pain / discomfort $26 \%$, followed by anxiety / depression $16 \%$, and the least damage was in the state of mobility $7 \%$. These data are consistent with data reported in recent research in the medical literature. $(23,24)$

We can state through this study that the average values of the EQ-5D index are lower in women than in men given in accordance with other studies in the literature. $(25,26)$ 


\section{PUBLIC HEALTH AND MANAGEMENT}

A possible explanation for this variation may be the female temperament more willing to notice changes in health and men seem more confident in their ability to control disease and less often make depressive or anxiety phenomena.(27)

The results obtained by this study also have a number of limitations, first of all that the study groups were relatively small and it was not possible to capture with great fidelity all the medical and social components that influence the decrease in quality of life (HRQoL). From the group of patients without metabolic syndrome, it is worth noting the presence of diseases with the potential to influence the quality of life in the future. Thus, hypertension is present in about $30 \%$, osteo-articular diseases in $27 \%$, liver diseases in $11 \%$, gastrointestinal diseases in $17 \%$ and diabetes in $12 \%$ of cases.On the other hand, a series of habits harmful to health such as: smoking, sedentary lifestyle, frequent alcohol consumption, hyperlipidic and hypersodium diet, can be longterm factors that can lead to decreased quality of life. In this sense, it is necessary to study in larger groups the involvement of these factors in determining the quality of life.

\section{CONCLUSIONS}

Measuring the impact on the quality of life in people with morbidities which can be associated with metabolic syndrome is frequently reported in research in recent years. In this study we were able to establish that the lowest values of the pain / discomfort dimension are found especially in the age groups 55-64, and of the mobility and self-care dimension are found in the 65-74 age group.

Metabolic syndrome has the ability to influence the quality of life especially through the dimensions of physical mobility and through the pain and discomfort caused by selfcare activities, especially in women. Also, in our research we found that the dimension of anxiety/ depression seems to be less important in influencing the quality of life.

In this sense, new studies are needed on larger groups that can accurately capture the changes caused by the metabolic syndrome that affects the quality of life.

\section{REFERENCES}

1. Zhijun Tan, Ying Liang, Siming Liu, Wenjun Cao, Haibo Tu, Lingxia Guo, and Yongyong Xu. Health-Related Quality of Life as Measured with EQ-5D among Populations wit hand without Specific Chronic Conditions: A Population-Based Survey in Shaanxi Province, ChinaPLoS One. 2013;8(7):e65958. Published online 2013 Jul 2. doi: 10.1371/journal.pone.0065958 PMCID: PMC3699581.

2. Wille N, Badia X, Bonsel G, Burström K, Cavrini G, Devlin N, Egmar AC, Greiner W, Gusi N, Herdman M, Jelsma J, Kind P, Scalone L, Ravens-Sieberer U. Development of the EQ-5D-Y: a child-friendly version of the EQ-5D. Qual Life Res. 2010;19(6):875-86. doi: 10.1007/s11136-010-9648-y. PMID: 20405245; PMCID: PMC2892611.

3. EuroQol Research Foundation. EQ-5D-Y User Guide, Version 2.0, 2020. Available from: https://euroqol.org/publications/user-guides/.Accessed on 12.05.2021.

4. https://euroqol.org/eq-5d-instruments/eq-5d-51about/valuation-standard-value-sets/Accessed 07.06.2021.

5. Janssen MF, Pickard AS, Golicki D, Gudex C, Niewada M, Scalone L, Swinburn P, Busschbach J. Measurement properties of the EQ-5D-5L compared to the EQ-5D-3L across eight patient groups: a multi-country study. Qual Life Res. 2013;22(7):1717-27. doi: 10.1007/s11136-012-
0322-4. PMID: 23184421; PMCID: PMC3764313.

6. van Hout B, Janssen MF, Feng YS, Kohlmann T, Busschbach J, Golicki D, Lloyd A, Scalone L, Kind P, Pickard AS. Interim scoring for the EQ-5D-5L: mapping the EQ-5D-5L to EQ-5D-3L value sets. Value Health. 2012;15(5):708-15. doi: 10.1016/j.jval.2012.02.008. PMID: 22867780.

7. Dyer MT, Goldsmith KA, Sharples LS, Buxton MJ. A review of health utilities using the EQ-5D in studies of cardiovascular disease. Health Qual Life Outcomes. 2010;8:13. doi:10.1186/1477-7525-8-13. PMID: 20109189; PMCID: PMC2824714.

8. Batóg P, Rencz F, Péntek M, Gulácsi L, Filipiak KJ, Prevolnik Rupel V, Simon J, Brodszky V, Baji P, Závada J, Petrova G, Rotar A, Golicki D. EQ-5D studies in cardiovascular diseases in eight Central and Eastern European countries: a systematic review of the literature. Kardiol Pol. 2018;76(5):860-870. doi: 10.5603/KP.a2018.0033. PMID: 29350378.

9. Golicki D, Dudzińska M, Zwolak A, Tarach JS. Quality of life in patients with type 2 diabetes in Poland comparison with the general population using the EQ-5D questionnaire, Adv Clin Exp Med, doi: 10.17219/acem/38137.

10. Bulamu NB, Kaambwa B, Ratcliffe J. A systematic review of instruments for measuring outcomes in economic evaluation within aged care. Health Qual Life Outcomes. 2015 Nov;13:179. DOI: 10.1186/s12955-0150372-8. PMID: 26553129; PMCID: PMC4640110.

11. Yang $Y$, Brazier J, Longworth L. EQ-5D in skin conditions: an assessment of validity and responsiveness. Eur J Health Econ. 2015;16(9):927-939. doi:10.1007/s10198-014-0638-9. PMID: 25358263; PMCID: PMC4646948.

12. Schwenkglenks M, Matter-Walstra K. Is the EQ-5D suitable for use in oncology? An overview of the literature and recent developments. Expert Rev Pharmacoecon Outcomes Res. 2016;16(2):207-219. doi:10.1586/14737167.2016.1146594. PMID: 26808097.

13. Shim J, Hamilton DF. Comparative responsiveness of the PROMIS-10 Global Health and EQ-5D questionnaires in patients undergoing total knee arthroplasty. Bone Joint $\mathrm{J}$. 2019;101-B(7):832-837. doi:10.1302/0301620X.101B7.BJJ-2018-1543.R1. PMID: 31256677 ; PMCID: PMC6616061.

14. Szende A, Janssen B, Cabases J, editors. Self-Reported Population Health: An International Perspective based on EQ-5D. Dordrecht (NL): Springer; 2014. DOI: 10.1007/978-94-007-7596-1. PMID: 29787044.

15. Shiroiwa T, Fukuda T, Ikeda S, Igarashi A, Noto S, Saito $S$, Shimozuma K. Japanese population norms for preference-based measures: EQ-5D-3L, EQ-5D-5L, and SF-6D. Qual Life Res. 2016;25(3):707-19. doi: 10.1007/s11136-015-1108-2. PMID: 26303761; PMCID: PMC4759213.

16. Janssen MF, Lubetkin EI, Sekhobo JP, Pickard AS: The use of the EQ-5D preference-based health status measure in adults with Type 2 diabetes mellitus. Diabet Med. 2011;28:395-413.

17. eq5d: Methods for Analysing EQ-5D Data and Calculating EQ-5D Index Scores https://rdrr.io/cran/eq5d/

18. Hayes AJ, Clarke PM, Glasziou PG, Simes RJ, Drury PL, Keech AC: Can self-rated health scores be used for risk prediction in patients with type 2 diabetes? Diabetes Care. 2008;31:795-797.

19. Bagust A, Beale S. Modelling EuroQol health-related utility values for diabetic complications from CODE-2 


\section{PUBLIC HEALTH AND MANAGEMENT}

data.Health Econ. 2005;14:217-230.

20. Clarke P, Gray A, Holman R. Estimating utility values for health states of type 2 diabetic patients using the EQ5D(UKPDS 62). Med Decis Making. 2002;22:340-349.

21. Holmes J, McGill S, Kind P, Bottomley J, Gillam S, Murphy M. Health-related quality of life in type 2 diabetes (TARDIS-2). Value Health. 2000;3:47-51.

22. Redekop WK, Koopmanschap MA, Stolk RP, Rutten GE, Wolffenbuttel BH, Niessen LW: Health-related quality of life and treatment satisfaction in Dutch patients with type 2 diabetes. Diabetes Care. 2002;25:458-463.

23. Solli O, Stavem K, Kristiansen IS. Health-related quality of life in diabetes: The associations of complications with EQ-5D scores. Health and Quality of Life Outcomes. 2010;8:18

24. Holmes J, McGill S, Kind P, Bottomley J, Gillam S, et al. Health-related Quality of Life in Type 2 Diabetes (T2ARDIS-2). Value in Health 3. 2000;S47-S51.

25. Lee WJ, Song KH, Noh JH, Choi YJ, Jo MW. (2012) Health-Related Quality of Life Using the EuroQol 5D Questionnaire in Korean Patients with Type 2 Diabetes. Journal of Korean Medical Science. 2012;27:255-260

26. Redekop WK, Rutten G, Koopmanschap MA, Wolffenbuttel BHR, Stolk RP, et al. Health-related quality of life and treatment satisfaction in Dutch patients with type 2 diabetes. Diabetes Care. 2002;25:458-463.

27. Peyrot M, Rubin RR. Persistence of depressive symptoms in diabetic adults. Diabetes Care. 1999;22:448-452. 